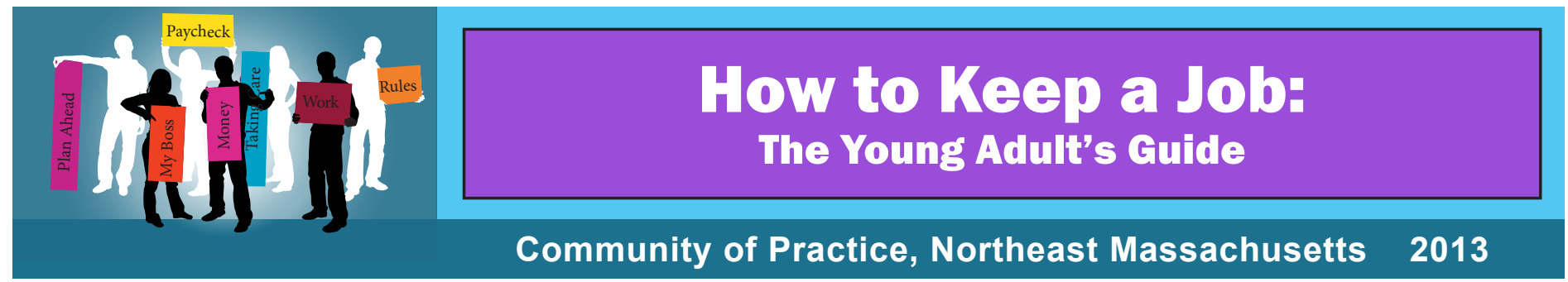

Starting and keeping a new job can be stressful for anyone. However, there are healthy ways to deal with this stress. This sheet has some tips to help you be more prepared to start and keep a new job, and hopefully be a little less stressed.

\title{
You Are Not Alone
}

Make sure you have people to talk to. Create a list of your supports. These people can be anyone that you talk to when you have problems: friends, family, teachers, role models, coworkers, church members, online friends. You may be surprised how many people can relate to how you are feeling right now.

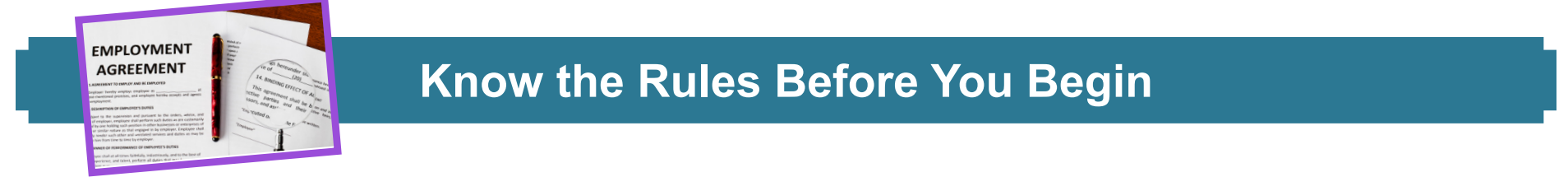

Most companies have a clear policy or handbook on many of these questions. Take the time to review it, and sit down with your boss to ask questions if any part of it is not clear before you begin working.

\section{Questions to ask}

- Cell Phones - Are they allowed at work? What about texting?

- Computer Use - Facebook, Twitter, and other social media sites are generally not appropriate while at work, check the policy.

- How do I request or schedule time off?

o How long do you have to work before you have personal time?

o Do you have to find someone to cover for you?

o Do you need to call a certain amount of time before your shift?

- Breaks - When do I get them? Where do I take them? What are the rules?

- Is there a uniform or dress code?

- Overtime - What are the rules? Is it in the Handbook?

- What are the guidelines for workplace relationships?

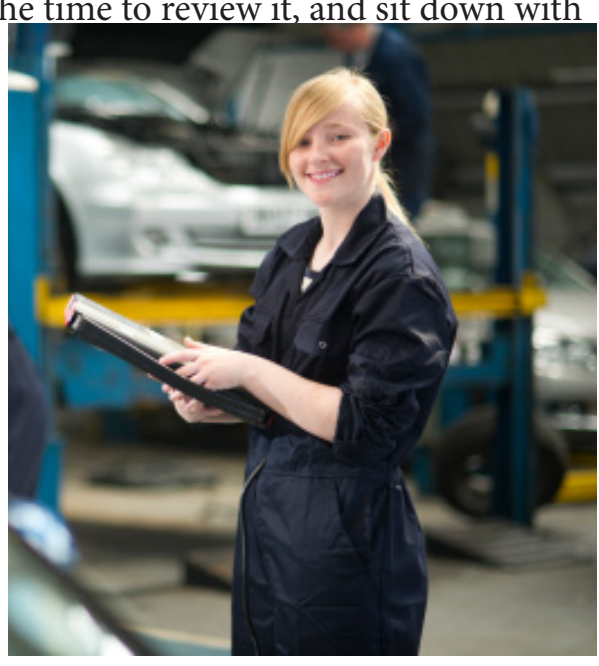

- Trainings

$\mathrm{O}$ Is there orientation training where policy and procedures are reviewed?

o Mandatory vs. Voluntary - (What trainings do I have to go to and which are optional?)

o Are there ways to advance your career?

o What trainings are paid for by the company? What trainings are non-paid?

- Harassment - What is it and what is the policy?

- $\quad$ Raises - How are they given?

- Probation Period - What does this mean? How long is it?

* If you are wondering if you should disclose your mental health condition on the job, please see the tip sheet, "Do I Tell My Boss" at: www.umassmed.edu/transitionsRTC/publication

\section{How to Succeed Once You Begin}

Here are suggestions to help you keep your job and avoid some mistakes people make when they start a new job.

- Keep track of your schedule-make an extra copy to keep in a safe place.

- Arrive on time - being late frequently will get you fired. If you are late once, explain why.

- Plan ahead

o How are you going to get to and from work? 
- Know your job description

O What's a backup plan to get to work?

o What should you do in an emergency?

o Just like an employee handbook, most jobs have a job description.

o Review your job description carefully and ask your supervisor any questions.

o Let your supervisor know if there are tasks that you aren't able to complete.

\section{Use Your Supervision Time Well}

Having supervision does not mean you are in trouble. Some bosses schedule time to meet with employees. Use this time to ask questions, build skills and be curious.

- Your boss does not expect you to know everything; it is ok to ask questions. There are no dumb questions.

- If your boss does not regularly schedule supervision, ask him or her if he or she could give you a few minutes each week to discuss how you are doing.

- Ask them what you are doing well, what they would like to see you change, and make an effort to apply this information to your work.

- It's ok to ask your boss for help with difficult situations (such as with customers, co-workers, etc.).

\section{Take Care of Yourself}

You can't be a good employee if you do not take care of yourself.

- Live a healthy lifestyle.

- Get enough sleep.

- Take care of any health issues you may have.

- Just as important is taking care of your emotional health.

o Schedule time to do the things that you enjoy

o Spend time with the people you love

O Don't stop doing the activities you love, work them into your schedule responsibly

o Reach out to people who care about you: friends, family, mentors, church members, counselors, etc.

\section{Reasons That Could Cause You to Lose Your Job}

- Being late

- Being rude

- Breaking the company rules

- Lying

- Using drugs or alcohol on the job
- Not being flexible

- Not showing up

- Stealing

- Being unprofessional (language, dress/hygiene, or sharing too much)

- Badmouthing the company (to other coworkers/on social media)

\section{Leaving a Job on a Good Note}

- Generally, you want to give your job advanced warning if you plan to quit, so you can leave on good terms.

- Most employers expect at least a two-week notice, but more can be helpful.

- Be honest and polite when telling your boss why you're leaving.

- Be careful about speaking negatively about former employers or coworkers when you leave a job.

- Doing the above can help you get a good reference from a past employer for future jobs.

For useful tips on how to get a job, download our free "How to Get a Job" tip sheet:

www.umassmed.edu/TransitionsRTC/publication

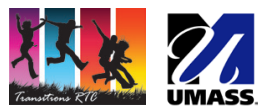

SPARC

Recommended citation: Northeast Massachusetts Community of Practice (2013) How to Keep a Job: The Young Adults Guide. Worcester, MA: University of Massachusetts Medical School, Department of Psychiatry, Systems and Psychosocial Advances Research Center.

This publication can be made available in alternative formats upon request through TransitionsRTC@umassmed.edu

The contents of this tip sheet were developed with funding from the US Department of Education, National Institute on Disability and Rehabilitation Research, and the Center for Mental Health Services, Substance Abuse and Mental Health Services Administration (NIDRR grant H133B090018). Additional funding provided by UMass Medical School's Commonwealth Medicine division. The content of this tip sheet does not necessarily reflect the views of the funding agencies and you should not assume endorsement by the Federal Government.

NïDILRR 5AMHSA Mass DMH Department of
Mental Health 